\title{
County level mortality and morbidity associated with PM2.5-related cancers in China based on satellite-derived PM2.5 data from 1998 to 2016: a forecasting and spatial analysis
}

Ke Ju

Sichuan University West China School of Public Health

WeiBin Liao

Sichuan University West China School of Public Health

Qian Zhou

Sichuan University West China Hospital

YaMin Gao

Northwest Minzu University College of Medicine

Jay Pan ( $\square$ panjie.jay@scu.edu.cn )

Sichuan University West China School of Public Health https://orcid.org/0000-0001-8040-8978

\section{Research}

Keywords: PM2.5-related cancers, regional transport, forecast, spatiotemporal analysis, China.

Posted Date: December 10th, 2019

DOI: https://doi.org/10.21203/rs.2.18389/v1

License: (c) (i) This work is licensed under a Creative Commons Attribution 4.0 International License.

Read Full License 
The manuscript is to be considered for the thematic series Environmental Justice and policy research.

County level mortality and morbidity associated with PM2.5-related cancers in China based on satellite-derived PM2.5 data from 1998 to 2016: a forecasting and spatial analysis

Ke Ju${ }^{1}$, Wei-Bin Liao ${ }^{1}$, Qian Zhou ${ }^{1}$, Ya-Min Gao ${ }^{2}$, Jay Pan ${ }^{1,3+}$

${ }^{1}$ West China School of Public Health and West China Fourth Hospital, Sichuan University, Chengdu, China;

${ }^{2}$ Medical College, Northwest Minzu University, Lanzhou, China;

${ }^{3}$ West China Research Center for Rural Health Development, Sichuan University, Chengdu, China.

\section{${ }^{+}$Corresponding to:}

Prof. Jay Pan, West China School of Public Health, Sichuan University, No. 17, Section 3, Ren Min Nan Road, Chengdu, Sichuan 610041, China; Email: panjie.jay@scu.edu.cn 


\section{Abstract}

Background: Ambient fine particulate matter $\left(\mathrm{PM}_{2.5}\right)$ pollution is becoming increasingly serious in China, and is a major risk factor for various cancers. Moreover, recent studies have indicated that there is an impact of $\mathrm{PM}_{2.5}$ from regional transport. We aimed to predict spatial distribution of cancers related to $\mathrm{PM}_{2.5}$, and draw a series of forecasting maps of these cancers.

Methods: A 1000-loops simulation was done to choose the optimal forecasting model between five alternative models: ridge regression, partial least square regression, regression tree, model tree, and the combined forecasting model. Then a kriging interpolation method was used to draw the forecasted cancer maps.

Results: The trend showed a gradual increase in the mortality and morbidity of breast cancer, pancreatic cancer, and all-cause cancer. We found a significant spatial autocorrelation between cancer incidence and $\mathrm{PM}_{2.5}$. Our results from forecasting showed a constant growth in mortality and morbidity of all cancers, and the kriging method suggested a similar spatial pattern. High morbidity and mortality areas were mainly in central-east and south-east China. We found a similar distribution pattern between $\mathrm{PM}_{2.5}$ concentration and mortality and morbidity associated with $\mathrm{PM}_{2.5}$-related cancers.

Conclusions: These findings serve as a valuable reference for the development of effective policies to reduce air pollution emissions, with the efforts from governments in high-risk areas.

Keywords: $\mathrm{PM}_{2.5}$-related cancers; regional transport; forecast; spatiotemporal analysis; China. 


\section{Introduction}

Over recent decades, China has witnessed extensive change in relation to diseases, with cancer becoming the leading cause of death post-2010 alongside rapid population growth and aging (Chen et al., 2016). In China in 2017, breast cancer and pancreatic cancer were counted in the top 25 leading causes of death, causing 169 and 133 years of life lost (YLL) per 100,000 persons, respectively(Zhou et al., 2019). Moreover, they all have suffered a significant increase in mortality rate in recent decades (Zhou et al., 2019).

Air pollution, particularly ambient particulate matters (with an aerodynamic diameter equal or less than $2.5 \mu \mathrm{m} ; \mathrm{PM}_{2.5}$ ), is becoming increasingly serious and is considered a major public health concern(Feng et al., 2016). Some previous studies have illustrated the $\mathrm{PM}_{2.5}$ are significantly associated with breast cancer and pancreatic cancer (Ancona et al., 2015; Chow et al., 2006; Hung et al., 2012; Parikh and Wei, 2016; Wei et al., 2012).

For China in recent decades many cities have suffered from severe air pollution due to rapid economic development and increased urbanization, particularly in the eastern region (Han et al., 2014; Rohde and Muller, 2015). The global burden of disease study for China in 2017 indicated particulate matter pollution was one of the top four risk factors contributing to both the number of deaths and percentage of disability-adjusted life years(Zhou et al., 2019). Many studies have illustrated the short-term effects of $\mathrm{PM}_{2.5}$ in China, and the majority of the findings demonstrate the increase in particulate matter is associated with higher non-accidental mortality, particularly cardiovascular and respiratory mortality (Chen et al., 2012; Lu et al., 2015). However, a limited number of studies focus on the long-term effects of $\mathrm{PM}_{2.5}$ since $\mathrm{PM}_{2.5}$ has not long been included in the Ambient Air Quality Standards and did not start to be regularly measured through ground-monitoring sites until 2012 and 2013, respectively. Furthermore, there has not been sufficient ground-monitoring sites to measure the effects of $\mathrm{PM}_{2.5}$ across the whole country (Geng et al., 2015; Han et al., 2017; Kan et al., 2009). To bridge the gap, rather than ground-monitoring data, the current study employed satellite-derived global surface $\mathrm{PM}_{2.5}$ concentrations across China, which are capable of providing a highresolution at $0.01^{\circ} \times 0.01^{\circ}$, as well as long-term and large-scale reference values.

Abundant evidence from previous studies have illustrated the considerable role of regional transport in $\mathrm{PM}_{2.5}$ pollution, indicating local air conditions can be affected by 
1 air pollution not only from local areas, but also adjacent regions (Chang et al., 2018;

2 Chang et al., 2019; Wang et al., 2015). Additionally, the 2015 national census reported there were approximately 247 million internal migrants who seek a better paid job in China (over 18 percent of the total population) and almost 65 percent of those migrants still live in the adjacent cities (Dhavan et al., 2017; Girardi et al., 2017). As a result, these migrants may be affected by air pollution from their former residences. These two factors are likely to result in a mixed influence in relation to air pollution; therefore, it is not ideal to use the local concentration of $\mathrm{PM}_{2.5}$ to reflect the influence of air pollution. The current study, then, accounts for regional transport to avoid overlooking the effect of adjacent areas.

Thus, the objectives of the current study can be divided into three parts. Firstly, by using high resolution and long-term data, considering the regional transportation of air pollution, and picking the ideal forecasting model, it will predict the spatial distribution of PM2.5-related cancers, namely all-cause cancer, breast cancer, and pancreatic cancer, mortality and morbidity; Then, it will draw a series forecasting maps, and find out what changes has happened, where are the top-risk of air pollution, and what trend of the cancer's mortality and morbidity; Last, it will put forward corresponding policy recommendations about where to attach more attention and what should the policymaker do.

\section{Materials and Methods}

\section{Satellite-derived annual $\mathbf{P M} 2.5$ concentration}

The annual means of global $\mathrm{PM}_{2.5}$ concentration at a spatial resolution of $0.01^{\circ} \times 0.01^{\circ}$ were collected from the Atmospheric Composition Analysis Group website created by Dalhousie University, and these were estimated by Van Donkelaar using multiple satellite products (i.e., MISR, MODIS Dark Target, MODIS and SeaWiFS Deep Blue, and MODIS MAIAC; (Van Donkelaar et al., 2014; Van Donkelaar et al., 2016). The GEOS-Chem chemical transport model related the aerosol optical depth to near-ground $\mathrm{PM}_{2.5}$. We used annual $\mathrm{PM}_{2.5}$ concentration with dust and sea-salt removed with a $0.01^{\circ} \times 0.01^{\circ}$ spatial resolution dataset to avoid disturbing uninhabited areas such as Taklimakan Desert and the East China Sea.

For each cancer registry area, we first spatially matched the polygon shapefile of cancer registry area with global surface annual $\mathrm{PM}_{2.5}$ concentration data. Then, calculated the annual mean $\mathrm{PM}_{2.5}$ concentration using the data of the grid point that fall within each cancer registry area from 1998 to 2016. 


\section{Cancers mortality and morbidity data for China}

All cancer(ICD-10 code: C00-C96), pancreatic cancer (ICD-10 code: C25), and breast cancer (ICD-10 code: C50) mortality and morbidity data from 2006 to 2014 were collected from the annual report released by the National Central Cancer Registry (NCCR) and Disease Prevention and Control Bureau (Ministry of Health). This is the most recent data since the NCCR typically holds off on releasing it for about five years. NCCR evaluated the registry data for completeness and validity.

There are 339 cancer registries which submitted the qualified data by 2014 and they lie in 31 provinces and municipalities, including 129 cities and 210 counties. The population covered by cancer registration areas in 2014 was 288,243,347 (146,203,891 males and 142,039,456 females), accounting for $21.07 \%$ of Chinese population. A total of 1294 cancer registries were reported from 2006 to 2014 (see Table 1). This study did not select the registries where the cancer mortality or morbidity was 0 or the annual mean $\mathrm{PM}_{2.5}$ concentration was lower than $10 \mu \mathrm{g} / \mathrm{m}^{3}$, according to the World Health Organization's (WHO) air quality guidelines. Additionally, due to the small spatial scale of some partial registries, we applied a large scale to such registries and recalculated the mortality and morbidity by population coverage on the county level. Finally, a total of 1194 registries were obtained for use in the study, and the annual cancer mortality and morbidity reflect the incidence and death of newly-increasing cancer cases occurring in a single year for the population covered.

We divided China into western, middle, and eastern areas for further exploration of the results in different regions, and the rule for this classification was based on the standard given by the National Statistics Bureau. Figure 1 and Figure S1 illustrate the spatial distribution of cancer registries for the current study in 2014 and from 2006 to 2013, respectively.

\section{Conceptual framework}

Many studies have revealed the relationship between $\mathrm{PM}_{2.5}$ exposure and the development of cancer mortality and morbidity, revealing an apparent time lag between them (Dreassi et al., 2005; Hystad et al., 2013; Song et al., 2017). Previous studies from China have demonstrated the time lag of $\mathrm{PM}_{2.5}$ exposure to cancer mortality and morbidity is 7 to 10 years (Han et al., 2017; Song et al., 2017; Zhang et al., 2014). Following these studies and integrating the aforementioned considerations (i.e., the 
1 influence of regional transport and internal migration), this study included two group 2 variables to establish the five alternative forecasting models (i.e., ridge regression, partial least squares regression, model tree, regression tree, and the combined forecasting model). The first group of variables contains a local annual mean $\mathrm{PM}_{2.5}$ concentration for the current year and previous eight years and are represented by Lag0 to Lag8. The other group contains the annual mean $\mathrm{PM}_{2.5}$ concentration calculated using the mean value of counties adjacent to a certain county in the current year and previous eight years and is represented by Slag0 to Slag8. This study calculated the spatial lag for a certain county based on its neighbor, which is based on sharing a common boundary or node. It is given by:

$$
\text { Slag }=\frac{\sum_{i=1}^{n} \mathrm{PM}_{2.5_{i}}}{\mathrm{n}}
$$

Where $\mathrm{PM}_{2.5}$ is the county unit concentration, $n$ is the total number of neighbors and $i$ denotes the neighbor for a certain county.

We then conducted the Pearson correlation analysis to evaluate the association between cancer morbidity and mortality, along with Lag0-Lag8 and Slag0-Slag8.

Then, we used the satellite-derived $\mathrm{PM}_{2.5}$ data from 1998 to 2016, as well as the cancer mortality and morbidity data from 2006 to 2014 to conduct analysis using five forecasting models. We compared their performances to reveal the optimal one. The five models and comparison criteria are explained in the following sections.

\section{Spatial autocorrelation}

Spatial autocorrelation was employed to examine the relationship between cancer mortality and morbidity and $\mathrm{PM}_{2.5}$ concentration in China. Globe Moran's I statistic, developed by Moran (Moran, 1950), is the key measure used in spatial autocorrelation. The equation for Moran's I statistic is:

$$
\mathrm{I}=\frac{\left(x_{i}-\bar{x}\right)\left(x_{j}-\bar{x}\right) \cdot n \cdot \sum_{i}^{n} \sum_{j}^{n} w_{i j}}{\sum_{i}^{n}\left(x_{i}-\bar{x}\right)^{2} \cdot\left(\sum_{i}^{n} \sum_{j}^{n} w_{i j}\right)}
$$

where I is Moran's I statistic for the autocorrelation coefficient, $n$ represents the number of spatial units, $i$ and $j$ denote the different grids, $x_{i}$ and $x_{j}$ represent the values at grids $i$ and $j, \bar{x}$ is the mean value averaged over each cell, and $w_{i j}$ is a matrix of spatial weight between $i$ and $j$. The standardized statistic $Z$ is always used to 
test the significance of Moran's I, which is given by:

$$
\begin{aligned}
& Z=I-E(I) / \operatorname{STD}(I) \\
& E(I)=-1 /(n-1) \\
& \operatorname{STD}=E\left(I^{2}\right)-E(I)^{2}
\end{aligned}
$$

The value of Moran's I usually ranges from -1 to 1 , with a positive value indicating a positive association and a negative value indicating a negative association, and such association is stronger when the value approaches -1 and 1 . The spatial relationships among counties or cities were characterized using the spatial weight matrix (Anselin, 2013). In the current study, an inverse distance matrix, which defines the impact of one feature on another feature decrease with distance, was used for spatial weights. An inverse-distance weight matrix was constructed in ArcGIS using the county-level pointshape file.

\section{Forecasting Models}

\section{Ridge regression}

Ridge regression analysis is a regression model that utilizes bias estimation with respect to the problem of a strong correlation between variables. It adds small positive quantities to the estimates to reduce the standard error when multicollinearity occurs (Hoerl and Kennard, 1970). It is given by the following:

$$
\begin{aligned}
\left(\hat{\beta}_{0}^{(\text {ridge })}, \hat{\boldsymbol{\beta}}^{(\text {ridge })}\right)=\operatorname{Min} \sum_{i}^{n}\left[\left(y_{i}-\beta_{0}-\beta_{i} x_{i}\right)^{2}+\lambda \sum_{j=1}^{\mathrm{p}} \beta_{\mathrm{j}}^{2}\right] \\
\hat{\boldsymbol{\beta}}(\mathbf{k})=\left(\mathbf{X}^{\prime} \mathbf{X}+\mathbf{k I}\right)^{-1} \mathbf{X}^{\prime} \mathbf{y} \\
=\left(\mathbf{X}^{\prime} \mathbf{X}+\mathbf{k} \mathbf{l}\right)^{-1} \mathbf{X}^{\prime} \mathbf{X}\left(\mathbf{X}^{\prime} \mathbf{X}\right)^{-1} \mathbf{X}^{\prime} \mathbf{y} \\
=\left(\mathbf{X}^{\prime} \mathbf{X}+\mathbf{k} \mathbf{l}\right)^{-1} \mathbf{X}^{\prime} \mathbf{X} \hat{\boldsymbol{\beta}}
\end{aligned}
$$

where $\mathrm{k}$ is the ridge-parameter, an important constant determining the ridge equation and is independent of $Y$; and when $\mathrm{k}$ varies in $(0, \infty)$, the $\hat{\boldsymbol{\beta}}(\mathrm{k})$, a linear transformation of least squares estimation, is the function of $\mathrm{k}$. The selection of a smaller value of $\mathrm{k}$ is recommended when the regression coefficients remain steady. We conducted the selection process and ridge regression model using the lmridge package based on $\mathrm{R}$ software.

\section{Partial least squares regression}


1 Partial least squares regression (PLSR) is a statistical method that brings together

2 the features of principal component analysis (PCA), canonical correlation analysis

3 (CCA), and multiple linear regression (MLR). It is also capable of partially dealing with

4 the problem of collinearity and providing predictions for cancer morbidity and mortality

5 (Abdi, 2010; Han et al., 2017). Such prediction is achieved through extracting from the

6 predictors a set of orthogonal factors called latent variables which contain the best

7 predictive power. We performed the selection process and PLSR regression model using

8 the plr package based on R software (Version 3.6.0).

\section{Model tree}

\section{Regression tree}

Regression tree is a machine-learning method used to construct prediction models from data (Breiman, 2017). The prediction models are obtained by recursively partitioning the whole data and fitting a sample prediction model for each partition. The predictions for these partitions are given by the mean value of the dependent variable in that partition. The splitting criterion maximizes the between-groups sum of squares in a simple analysis of variance, as follows:

$$
\begin{array}{r}
\text { Max: } \text { SS }_{\mathrm{T}}-\left(\mathrm{SS}_{\mathrm{L}}+\mathrm{SS}_{\mathrm{R}}\right) \\
\mathrm{SS}_{\mathrm{T}}=\sum\left(\mathrm{y}_{\mathrm{i}}-\overline{\mathrm{y}}\right)^{2}
\end{array}
$$


where $S_{T}$ is the sum of squares for the tree node, and $S_{R}$ and $S_{L}$ are the sum of squares for the right and left branches, respectively. The process was conducted using the rpart package based on $\mathrm{R}$ software.

\section{Combined forecasting model}

The combined forecasting model was used to aggregate information from different forecasting models based on the evidence given in previous studies, all of which found the combined model suffers less influence from a specific method, presenting an optimal result (Aiolfi et al., 2010; Armstrong, 2001; Bates and Granger, 1969; Clemen, 1989). In the current study, the coefficient of variation method was used to gain a specific weight for each abovementioned forecasting model to deal with the relative accuracy and covariances of forecast errors (Diebold and Lopez, 1996; Timmermann, 2006). Following this, those forecasting models were combined in a linear combination through the weight as follows:

$$
\begin{gathered}
\mathrm{V}_{\mathrm{i}}=\frac{\sigma_{i}}{\overline{\mathrm{X}}_{i}}(i=1,2 \ldots n) \\
w_{i}=\mathrm{V}_{\mathrm{i}} / \sum_{i=1}^{n} \mathrm{~V}_{\mathrm{i}}
\end{gathered}
$$

$$
\mathbf{Y}=\sum_{i=1}^{n} w_{i} f_{i}=w_{1} f_{1}+w_{i} f_{i}+\ldots+w_{n} f_{n}
$$

where $V_{i}$ represents the coefficient of variation of $i_{t h}$ forecasting model, $\sigma_{i}$ is the standard deviation of the $i_{t h}$ forecasting model, and $\bar{x}_{i}$ is the mean value of the prediction. Additionally, $w_{i}$ is the weight of the $i_{t h}$ forecasting model in the combination forecasting model, $\mathrm{Y}$ is the prediction made using the combined forecasting model, and $f_{i}$ is the prediction of the $i_{t h}$ forecasting model.

\section{Evaluation and validation}

In this study, we conducted an error analysis to evaluate the performance of the models used based on differences in accuracy between observed and predicted cancer mortality and morbidity. Several model evaluation indices were calculated, including the mean square error (MSE), the root mean square error (RMSE), mean absolute error 
1 (MAE), mean absolute percentage error (MAPE), Theil inequality coefficient (Theil

2 IC), and covariance proportion (CP). These indices are expressed as follows:

$$
\mathrm{MSE}=\frac{1}{n} \sum_{i=1}^{n}\left(y_{i}-\hat{y}_{i}\right)^{2} \mathrm{RMSE}=\sqrt{\frac{1}{n} \sum_{i=1}^{n}\left(y_{i}-\hat{y}_{i}\right)^{2}}, \mathrm{MAE}=\frac{1}{n} \sum_{i=1}^{n}\left|y_{i}-\hat{y}_{i}\right|,
$$

$4 \quad$ MAPE $=\frac{1}{n} \sum_{i=1}^{n}\left|\frac{y_{i}-\hat{y}_{i}}{y_{i}}\right| \cdot 100 \%$, Theil IC $=\frac{\sqrt{\frac{1}{n} \sum_{i=1}^{n}\left(y_{i}-\hat{y}_{i}\right)^{2}}}{\sqrt{\frac{1}{n} \sum_{i=1}^{n} y_{i}^{2}}+\sqrt{\frac{1}{n} \sum_{i=1}^{n} \hat{y}_{i}^{2}}}$,

$5 \quad \mathrm{BP}=\frac{\left(\overline{\hat{y}}_{i}-\bar{y}_{i}\right)^{2}}{\sum_{i=1}^{n}\left(\hat{y}_{i}-y_{i}\right)^{2} / n}, \mathrm{VP}=\frac{\left(\sigma_{\hat{y}_{i}}-\sigma_{y_{i}}\right)^{2}}{\sum_{i=1}^{n}\left(\hat{y}_{i}-y_{i}\right)^{2} / n}$, and $\mathrm{CP}=1-\mathrm{BP}-\mathrm{VP}$.

where $y_{i}$ is the observed value; $\hat{y}_{i}$ is the predicted value; $\bar{y}_{i}$ is the mean value of $y_{i} ; \overline{\hat{y}}_{i}$ is the mean value of $\hat{y}_{i}$; and $\sigma_{y_{i}}$ and $\sigma_{\hat{y}_{i}}$ are the standard deviation values of the observed and predicted cancer mortality and morbidity, respectively. The smaller values for MSE, RMSE, MAE, MAPE, and Theil IC indicate the lower error for the predicted value, while the larger value of CP indicates improved consistency between forecasted and observed.

We also conducted a 1000-loops simulation to get a milder estimation of the performance of each forecasting model to avoid selection bias. Specifically, first, the data in its entirety were randomly allocated to a training set and testing set, where the training set accounted for 90 percent and the testing set accounted for 10 percent. Second, we fitted every method using the training set. Finally, we calculated the performance of the validation and evaluation using the testing set. Following this, we repeated the whole step 1000 times and calculated the mean value and selected an ideal model (i.e., that with the best performance). We also changed the proportion of the training and testing sets in order to conduct the robustness test, where 85, 80, 75 and $70 \%$ accounted for the training set; and 15, 20, 25 and 30\% accounted for the testing set.

Finally, the annual cancers mortality and morbidity data for 2408 counties or cities from 2015 to 2016 were obtained using the ideal forecasting model, and the gridded spatial distribution of cancers mortality and morbidity in 2015 to 2016 was obtained using the Kriging interpolation in ArcGIS 10.2. 
Results

\section{Cancer mortality and morbidity}

There were 3,679,921 and 2,295,634 cancer morbidity and mortality cases reported in China from 2006 and 2014, of which 261,474 (7.11\%) were breast cancer, 91,646 (2.5\%) were pancreatic cancer in morbidity, 74,705 (3.25\%) were breast cancer, and $83,227(3.63 \%)$ were pancreatic cancer in mortality. Within both breast and pancreatic cancers, urban areas showed a higher rate of morbidity and mortality. Table S4A - S4C presents the nation-level morbidity and mortality of all cancer, breast cancer and pancreatic cancer from 2006 to 2014. Of the crude rate of those cancers, morbidity and mortality showed an increasing trend. Figure 3 and Figure S2 - S9 present the spatial distribution of morbidity and mortality of those cancers in 2014 and in from 2006 to 2013, respectively. It presents a constant spatial variation in those cancerswhether mortality or morbidity - that the observed high reported value registries are mainly concentrated in the eastern region, especially the Yangzi River Delta (YRD).

\section{Spatial distribution of $\mathbf{P M}_{2.5}$}

Among 1,194 cancer registry areas from 2006 to 2014, 1,192 areas had annual mean $\mathrm{PM}_{2.5}$ concentrations greater than $10 \mu \mathrm{g} / \mathrm{m}^{3}$ (the WHO air quality guidelines recommendation for $\mathrm{PM}_{2.5}$ annual mean concentrations), 1,167 areas had greater than $15 \mu \mathrm{g} / \mathrm{m}^{3}$ (WHO Interim target-3 (IT-3)), 1,033 areas had greater than $25 \mu \mathrm{g} / \mathrm{m}^{3}$ (WHO Interim target-2 (IT-2)), and 859 cancer registry areas had greater than $35 \mu \mathrm{g} / \mathrm{m}^{3}$ (WHO Interim target-1 (IT-1)). Figure 2 presents the spatial distribution of nineteen-year-long mean $\mathrm{PM}_{2.5}$ concentration in China. The majority of the high $\mathrm{PM}_{2.5}$ concentration appeared east of the Hu Line, which was proposed by Huanyong Hu in 1935 to illustrate China's demographic distribution and is also consistent with population and industry distribution in China. There was a significant difference in the spatial patterns of the annual mean $\mathrm{PM}_{2.5}$ for eastern and western China. The overall average $\mathrm{PM}_{2.5}$ concentration for eastern China was two times higher than that for western China.

\section{Pearson correlation analysis}

The results of Pearson correlation analysis - whether mortality or morbidity demonstrated that both local and spatial lag had a long and positive effect on all 
targeted cancers mortality and morbidity. The results in their entirety are presented in Table S1A - S1C. Compare to the local lag and spatial lag exposure to ambient $\mathrm{PM}_{2.5}$, the spatial lag effect was not stronger than the local $\mathrm{PM}_{2.5}$ exposure, which may depend on the apportionment of surrounding $\mathrm{PM}_{2.5}$ concentration. Generally, both local and spatial lag had long and positive effects on lung cancer mortality and morbidity.

\section{Globe spatial autocorrelation}

The use of the globe Moran's I statistic demonstrated that the mortality and morbidity of all cancer, pancreatic cancer, and breast cancer were significantly spatially autocorrelated in China for most of the years studied. Figure 4 presents the result in 2014 and Tables S5A - S5C present the results from 2006 to 2013, respectively. Additionally, the annual $\mathrm{PM}_{2.5}$ concentration showed a significant and positive spatial autocorrelation for each year (see Figure 5). As shown, an increasing trend was found in the Z-score for the globe Moran's I statistic, which indicates it is less possible for $\mathrm{PM}_{2.5}$ in a region to follow a random distribution.

\section{Forecasting PM2.5-related cancers mortality and morbidity}

Table S2A - S2C illustrate the model evaluation of five forecasting models for targeted cancers in mortality and morbidity, which indicate that the combination forecasting model performed best among those alternative models in those evaluations, except in the forecasting of mortality in breast cancer. Results of sensitivity analysis in different scenarios were constant, demonstrating that the ridge regression performs best in breast cancer morbidity forecasting and the combination model performance was superior in other scenes, and, therefore, we selected them as the forecasting models, depending on different scenes (Table S3A - S3L).

Figure $6-8$ illustrated the forecast of mortality and morbidity of all cancer, pancreatic cancer, and breast cancer due to $\mathrm{PM}_{2.5}$ exposure, respectively. All three categories — whether a morbidity or mortality forecast - showed a gradual rise from the western region of China to the eastern region, and the most affected areas were shown to be in China's eastern-coastal region, including Beijing-Tianjin-Hebei (BTH), YRD, and Northeast China (NEC), which is consistent with the distribution of $\mathrm{PM}_{2.5}$. When we compare the results of all cancer in 2015 and 2016, we can find that the whole trend shows a slightly increase, and northeastern China is expected to significantly increase 
1 in both morbidity and mortality in 2016, while eastern area has shown a downward trend. The situation in breast cancer and pancreatic cancer shows a slightly change. Like the predicted results of all cancer, breast cancer and pancreatic cancer mortality and morbidity in eastern China are expected to show slight declines, but the results in some western areas are predicted to increase. However, the morbidity and mortality of breast cancer and pancreatic cancer in western China are expected to show a relatively significant increase. At the same time, the changes in the predicted results of these two cancers in Northeast China, except for pancreatic cancer mortality, are expected to show a downward trend, although their forecast levels in 2016 are still higher than most parts of the country.

\section{Discussion and Conclusion}

In this study, we applied a collection of long-term and large-scale databases combined with spatiotemporal analysis to generate forecasting maps on spatiotemporal patterns of the mortality and morbidity related to $\mathrm{PM}_{2.5}$ concentration in China. We found the highest cancer mortality and morbidity areas were mostly located in the eastern, northeastern, and southern regions of China, which is consistent with population-intensity and industrial distribution. There are several noteworthy differences in this study compared with previous studies. First, we took the spatial $\mathrm{PM}_{2.5}$ concentrations into consideration, which is a significant advancement compared with the use of local concentrations only. Having taken into consideration the use of local and spatial $\mathrm{PM}_{2.5}$ concentrations to deal with the air pollution associated with regional transport and internal migration, we have ensured the results presented in the study are more comprehensive. Second, the combination of high-resolution $\mathrm{PM}_{2.5}$ concentration from 1998 to 2016, cancer databases covering hundreds of millions of people, and spatiotemporal analysis has allowed us to provide an overall description of China. Accordingly, the inclusion of 2408 counties in China out of the possible 2860 has provided a larger evidence base and improved spatial richness. Third, a 1000-loops simulation was conducted to evaluate the performance of five forecasting models. Compared with choosing a training set and testing set manually, this simulation is capable of significantly reducing the selection bias and generating a more reliable result. Additionally, our study attempted to make contributions to the spatiotemporal 
1 perspectives of the relationship between all cancer, pancreatic cancer, breast cancer, and $\mathrm{PM}_{2.5}$ concentration simultaneously, which is an area limited studies exist.

The current study demonstrated a spatial association between $\mathrm{PM}_{2.5}$-related cancers morbidity and mortality and $\mathrm{PM}_{2.5}$ concentration during the current year and previous eight years. The concentration rate of $\mathrm{PM}_{2.5}$ with an increasing trend and a $0.341 \mu \mathrm{g} / \mathrm{m}^{3}$ annual average increase trend was identified from 1998 to 2016 in China. Results from the spatial autocorrelation demonstrated that the mortality and morbidity of those cancers and $\mathrm{PM}_{2.5}$ concentration were significantly spatially autocorrelated for each year in China. We also found a spatial association between cancer morbidity and mortality and satellite-derived $\mathrm{PM}_{2.5}$ concentration. Additionally, the simulation analysis and forecasting model in the current study provided a useful tool in the risk assessment of $\mathrm{PM}_{2.5}$. It verified the important role of regional transportation of air pollution and immigration, at the same time, it also verifed the high-risk of air pollution in China, namely the BTH, YRD, and NEC areas. Further, besides the slightly increase trend was found in the targeted cancers mortality and morbidity, the results also suggest that the gap between eastern and western China is predicted to narrow, and the results of Northeastern China are predicted to increase significantly, while the western region shows an upward trend for specific cancers. In addition, the eastern area remains a highrisk for air pollution despite the slightly downward trend.

Although some evidence showed the air pollution in China had being decreased from around 2008, in this current study, there are still more than $70 \%$ of registries areas in China having the $\mathrm{PM}_{2.5}$ over $35 \mu \mathrm{g} / \mathrm{m}^{3}$. Recently, air pollution from regional transport has received considerable attention, but most studies aiming to predict the distribution of $\mathrm{PM}_{2.5}$-related cancers have only focused on local air pollution (Chang et al., 2018; Guo et al., 2016; Han et al., 2017; Wang et al., 2015). In this study, we found the three regions where high concentrations of $\mathrm{PM}_{2.5}$ are mainly located (i.e., BTH, YRD and NEC), which is a finding consistent with previous studies (Bai et al., 2019; He et al., 2019; $\mathrm{Hu}$ et al., 2014). Although the constitutes of $\mathrm{PM}_{2.5}$ are different in the BTH, it was found that an average of approximately $34 \%$ of $\mathrm{PM}_{2.5}$ in Beijing could be attributed to outside sources-even Hebei province contributed $50-70 \%$ of the $\mathrm{PM}_{2.5}$ concentration in Beijing during the period of the eastern and southern winds (Gao et al., 
1 2014; Gao et al., 2018). This aligns with the results from the Environmental Protection

2 Bureau which showed $28-36 \%, 22-34 \%$ and $15-30 \%$ of $\mathrm{PM}_{2.5}$ emission sources in

3 Beijing, Tianjin and Hebei, respectively, were from trans-regional and long-distance transmissions. In terms of the YRD, although rapid development and urbanization have aggravated the air pollution in this area, Ming et al. (2017) found that the areas of central and northern China significantly contributed to its $\mathrm{PM}_{2.5}$ concentration and chemical composition during the winter months due to the coal combustion associated with heating, showing the movement of $\mathrm{PM}_{2.5}$ across three pollution processes. For the NEC, previous studies have shown that coal combustion, vehicle exhaust, and metallurgical activities are the main local contributors to aerosol pollution, where the air pollution showed movement from BTH to NEC (Han et al., 2010; Miao et al., 2018). On the other hand, with the process of reform and opening up in China, the number of internal migrants is rapidly increasing. According to the national population sampling survey, the majority of internal migrants prefer to move within their original province, and the trans-province migrants likely prefer to move to neighboring provinces or megacities - for this study, the majority of trans-province migrations were shown to be in the BTH and YRD areas, which were found to be heavily $\mathrm{PM}_{2.5}$-polluted regions. It is crucial to consider the impact of internal migrants when properly dealing with the relationship between $\mathrm{PM}_{2.5}$ and $\mathrm{PM}_{2.5}$-related cancers. Internal migrants can influence the epidemic characteristics of cancer mortality and morbidity, as well as ambient air quality. Evidence from previous studies has shown that internal migration has largely reduced ambient $\mathrm{PM}_{2.5}$ concentration in China (Aunan and Wang, 2014; Ru et al., 2015; Shen et al., 2018; Shen et al., 2017). In this study, therefore, we proposed spatial $\mathrm{PM}_{2.5}$ concentration to deal with China's regional transport and internal migrants.

The satellite-derived $\mathrm{PM}_{2.5}$ data were compared with globe ground-based monitors for the residual bias through geographically weighted regression (GWR). The result showed that the satellite-derived $\mathrm{PM}_{2.5}$ were strongly aligned with our study sample cross-validation $\mathrm{PM}_{2.5}$ concentrations from the monitors used (Van Donkelaar et al., 2014; Van Donkelaar et al., 2016). Compared with the ground-based monitors, satellitederived $\mathrm{PM}_{2.5}$ data showed greater coverage, especially in those areas not covered by limited ground-based monitors (Wang et al., 2018), The dust and sea salt removed annual $\mathrm{PM}_{2.5}$ concentration, where a $0.01^{\circ} \times 0.01^{\circ}$ spatial resolution was used, which 
1 may result in an underestimation but also avoids the disturbance of uninhabited areas

2 such as the Taklimakan Desert and the East China Sea. The completeness and validity tests ensured the cancer data extracted from hundreds of cancer registries covering over 280 million people were of a high quality. A robustness test including those registries indicated a constant trend.

The predicted cancer morbidity and mortality gained through the use of $\mathrm{PM}_{2.5}$ concentration data provides new credible evidence to help identify the spatial distribution and temporal changing pattern of $\mathrm{PM}_{2.5}$-related cancers mortality and morbidity in different $\mathrm{PM}_{2.5}$-contaminated regions in China. Moreover, the specific and accurate estimation of the spatiotemporal distribution of $\mathrm{PM}_{2.5}$-related cancer morbidity and mortality, especially in terms of regional transport, provides important information for government and policy-makers regarding priority areas for regional air pollution prevention and control in China. More importance should be attached in the western and northeastern area, while the management in eastern China should not be relaxd. Besides, the policy-maker should not noly focus on the local air pollution governance, but the joint management with adjacent areas is equally important.

This study contains the following limitations. First, the mean values of the $\mathrm{PM}_{2.5}$ concentration of adjacent counties were used to characterize the impact of the regional transport of $\mathrm{PM}_{2.5}$ and internal migration, which may be limited in terms of the influence of distance, spatial distribution of $\mathrm{PM}_{2.5}$, and direction of wind and migration. Second, we failed to control for some population characteristics related to those cancers, such as smoking and drinking, as such data on a county level was not available for collection and analysis. 


\section{Reference:}

Abdi, H., 2010. Partial least squares regression and projection on latent structure regression (PLS Regression). Wiley Interdisciplinary Reviews: Computational Statistics 2, 97-106.

Aiolfi, M., Capistran, C., Timmermann, A., 2010. Forecast combinations. CREATES research paper. Ancona, C., Badaloni, C., Mataloni, F., Bolignano, A., Bucci, S., Cesaroni, G., Sozzi, R., Davoli, M., Forastiere, F., 2015. Mortality and morbidity in a population exposed to multiple sources of air pollution: A retrospective cohort study using air dispersion models. 137, 467-474.

Anselin, L., 2013. Spatial econometrics: methods and models. Springer Science \& Business Media. Armstrong, J.S., 2001. Combining forecasts, Principles of forecasting. Springer, pp. 417-439.

Aunan, K., Wang, S., 2014. Internal migration and urbanization in China: Impacts on population exposure to household air pollution (2000-2010). Science of The Total Environment 481, 186-195. Bai, K., Ma, M., Chang, N.-B., Gao, W., 2019. Spatiotemporal trend analysis for fine particulate matter concentrations in China using high-resolution satellite-derived and ground-measured PM2. 5 data. Journal of environmental management 233, 530-542.

Bates, J.M., Granger, C.W.J., 1969. COMBINATION OF FORECASTS. Operational Research Quarterly 20, 451-\&.

Breiman, L., 2017. Classification and regression trees. Routledge.

Chang, X., Wang, S., Zhao, B., Cai, S., Hao, J., 2018. Assessment of inter-city transport of particulate matter in the Beijing-Tianjin-Hebei region. Atmospheric Chemistry and Physics 18, 4843-4858.

Chang, X., Wang, S., Zhao, B., Xing, J., Liu, X., Wei, L., Song, Y., Wu, W., Cai, S., Zheng, H., Ding, D., Zheng, M., 2019. Contributions of inter-city and regional transport to PM2.5 concentrations in the Beijing-Tianjin-Hebei region and its implications on regional joint air pollution control. Science of The Total Environment 660, 1191-1200.

Chen, R., , o.B.o.t.C.C.G., Kan, H., , o.B.o.t.C.C.G., Chen, B., , o.B.o.t.C.C.G., Huang, W., , o.B.o.t.C.C.G., Bai, Z., , o.B.o.t.C.C.G., Song, G., , o.B.o.t.C.C.G., Pan, G., , o.B.o.t.C.C.G., 2012. Association of Particulate Air Pollution With Daily Mortality: The China Air Pollution and Health Effects Study. American Journal of Epidemiology 175, 1173-1181.

Chen, W., Zheng, R., Baade, P.D., Zhang, S., Zeng, H., Bray, F., Jemal, A., Yu, X.Q., He, J., 2016. Cancer statistics in China, 2015. CA: a cancer journal for clinicians 66, 115-132.

Chow, J.C., Watson, J.G., Mauderly, J.L., Costa, D.L., Wyzga, R.E., Vedal, S., Hidy, G.M., Altshuler, S.L., Marrack, D., Heuss, J.M., Wolff, G.T., Arden Pope lii, C., Dockery, D.W., 2006. Health Effects of Fine Particulate Air Pollution: Lines that Connect. Journal of the Air \& Waste Management Association 56, 1368-1380.

Clemen, R.T., 1989. COMBINING FORECASTS - A REVIEW AND ANNOTATED-BIBLIOGRAPHY. International Journal of Forecasting 5, 559-583

Dhavan, P., Dias, H., Creswell, J., Weil, D., 2017. An overview of tuberculosis and migration. The International Journal of Tuberculosis and Lung Disease 21, 610-623.

Diebold, F.X., Lopez, J.A., 1996. 8 Forecast evaluation and combination. Handbook of statistics 14, 241-268.

Dreassi, E., Biggeri, A., Catelan, D., 2005. Space-time models with time-dependent covariates for the analysis of the temporal lag between socioeconomic factors and lung cancer mortality. 24 , 1919-1932.

Feng, S., Gao, D., Liao, F., Zhou, F., Wang, X., 2016. The health effects of ambient PM2. 5 and potential mechanisms. Ecotoxicology and environmental safety 128, 67-74.

Gao, J., Tian, H., Cheng, K., Lu, L., Wang, Y., Wu, Y., Zhu, C., Liu, K., Zhou, J., Liu, X., Chen, J., Hao, J., 2014. Seasonal and spatial variation of trace elements in multi-size airborne particulate matters of Beijing, China: Mass concentration, enrichment characteristics, source apportionment, chemical speciation and bioavailability. 99, 257-265.

Gao, J., Wang, K., Wang, Y., Liu, S., Zhu, C., Hao, J., Liu, H., Hua, S., Tian, H., 2018. Temporal-spatial characteristics and source apportionment of PM2.5 as well as its associated chemical species in the Beijing-Tianjin-Hebei region of China. Environmental Pollution 233, 714-724. 
Geng, G., Zhang, Q., Martin, R.V., Van Donkelaar, A., Huo, H., Che, H., Lin, J., He, K., 2015. Estimating long-term PM2.5 concentrations in China using satellite-based aerosol optical depth and a chemical transport model. Remote Sensing of Environment 166, 262-270.

Girardi, E., Sañé Schepisi, M., Goletti, D., Bates, M., Mwaba, P., Yeboah-Manu, D., Ntoumi, F., Palmieri, F., Maeurer, M., Zumla, A., Ippolito, G., 2017. The global dynamics of diabetes and tuberculosis: the impact of migration and policy implications. International Journal of Infectious Diseases 56, 45-53.

Guo, Y., Zeng, H., Zheng, R., Li, S., Barnett, A.G., Zhang, S., Zou, X., Huxley, R., Chen, W., Williams, G., 2016. The association between lung cancer incidence and ambient air pollution in China: A spatiotemporal analysis. Environmental Research 144, 60-65.

Han, B., Kong, S., Bai, Z., Du, G., Bi, T., Li, X., Shi, G., Hu, Y., 2010. Characterization of Elemental Species in PM2.5 Samples Collected in Four Cities of Northeast China. Water, Air, \& Soil Pollution 209, 15-28.

Han, L., Zhou, W., Li, W., Li, L., 2014. Impact of urbanization level on urban air quality: A case of fine particles (PM 2.5 ) in Chinese cities. Environmental Pollution 194, 163-170.

Han, X., Liu, Y., Gao, H., Ma, J., Mao, X., Wang, Y., Ma, X., 2017. Forecasting PM2.5 induced male lung cancer morbidity in China using satellite retrieved PM2.5 and spatial analysis. Science of The Total Environment 607-608, 1009-1017.

He, Q., Gu, Y., Zhang, M., 2019. Spatiotemporal patterns of aerosol optical depth throughout China from 2003 to 2016. Science of The Total Environment 653, 23-35.

Hoerl, A.E., Kennard, R.W., 1970. RIDGE REGRESSION - BIASED ESTIMATION FOR NONORTHOGONAL PROBLEMS. Technometrics 12, 55-\&.

Hu, J., Wang, Y., Ying, Q., Zhang, H., 2014. Spatial and temporal variability of PM2. 5 and PM10 over the North China Plain and the Yangtze River Delta, China. Atmospheric Environment 95, 598609.

Hung, L.-J., Tsai, S.-S., Chen, P.-S., Yang, Y.-H., Liou, S.-H., Wu, T.-N., Yang, C.-Y., 2012. Traffic air pollution and risk of death from breast cancer in Taiwan: Fine particulate matter (PM2. 5) as a proxy marker. Aerosol Air Qual. Res 12, 275-282.

Hystad, P., Demers, P.A., Johnson, K.C., Carpiano, R.M., Brauer, M., 2013. Long-term residential exposure to air pollution and lung cancer risk. Epidemiology, 762-772.

Kan, H., Chen, B., Hong, C., 2009. Health impact of outdoor air pollution in China: current knowledge and future research needs. National Institute of Environmental Health Sciences.

Lu, F., Xu, D., Cheng, Y., Dong, S., Guo, C., Jiang, X., Zheng, X., 2015. Systematic review and metaanalysis of the adverse health effects of ambient PM2.5 and PM10 pollution in the Chinese population. Environmental Research 136, 196-204.

Miao, Y., Guo, J., Liu, S., Zhao, C., Li, X., Zhang, G., Wei, W., Ma, Y., 2018. Impacts of synoptic condition and planetary boundary layer structure on the trans-boundary aerosol transport from Beijing-Tianjin-Hebei region to northeast China. Atmospheric Environment 181, 1-11.

Moran, P.A., 1950. Notes on continuous stochastic phenomena. Biometrika 37, 17-23.

Parikh, P.V., Wei, Y., 2016. PAHs and PM2.5emissions and female breast cancer incidence in metro Atlanta and rural Georgia. 26, 458-466.

Quinlan, J.R., 1992. Learning with continuous classes.

Rohde, R.A., Muller, R.A., 2015. Air Pollution in China: Mapping of Concentrations and Sources. PLOS ONE 10, e0135749.

Ru, M., Tao, S., Smith, K., Shen, G., Shen, H., Huang, Y., Chen, H., Chen, Y., Chen, X., Liu, J., 2015. Direct energy consumption associated emissions by rural-to-urban migrants in Beijing. Environmental science \& technology 49, 13708-13715.

Shen, H., Chen, Y., Russell, A.G., Hu, Y., Shen, G., Yu, H., Henneman, L.R., Ru, M., Huang, Y., Zhong, Q., 2018. Impacts of rural worker migration on ambient air quality and health in China: From the perspective of upgrading residential energy consumption. Environment International 113, 290 299. 
Shen, H., Tao, S., Chen, Y., Ciais, P., Güneralp, B., Ru, M., Zhong, Q., Yun, X., Zhu, X., Huang, T., 2017. Urbanization-induced population migration has reduced ambient PM2. 5 concentrations in China. Science advances 3, e1700300.

Shi, Y., Matsunaga, T., Yamaguchi, Y., Li, Z., Gu, X., Chen, X., 2018a. Long-term trends and spatial patterns of satellite-retrieved PM 2.5 concentrations in South and Southeast Asia from 1999 to 2014. Science of The Total Environment 615, 177-186.

Shi, Y., Matsunaga, T., Yamaguchi, Y., Zhao, A., Li, Z., Gu, X., 2018b. Long-term trends and spatial patterns of PM 2.5 -induced premature mortality in South and Southeast Asia from 1999 to 2014. Science of The Total Environment 631-632, 1504-1514.

Song, C., He, J., Wu, L., Jin, T., Chen, X., Li, R., Ren, P., Zhang, L., Mao, H., 2017. Health burden attributable to ambient PM2.5 in China. Environmental Pollution 223, 575-586.

Timmermann, A., 2006. Forecast combinations. Handbook of economic forecasting 1, 135-196.

Van Donkelaar, A., Martin, R.V., Brauer, M., Boys, B.L., 2014. Use of satellite observations for longterm exposure assessment of global concentrations of fine particulate matter. Environmental health perspectives 123, 135-143.

Van Donkelaar, A., Martin, R.V., Brauer, M., Hsu, N.C., Kahn, R.A., Levy, R.C., Lyapustin, A., Sayer, A.M., Winker, D.M., 2016. Global estimates of fine particulate matter using a combined geophysical-statistical method with information from satellites, models, and monitors. Environmental science \& technology 50, 3762-3772.

Wang, L., Liu, Z., Sun, Y., Ji, D., Wang, Y., 2015. Long-range transport and regional sources of PM2.5 in Beijing based on long-term observations from 2005 to 2010. Atmospheric Research 157, 37-48.

Wang, Q., Wang, J., He, M.Z., Kinney, P.L., Li, T., 2018. A county-level estimate of PM 2.5 related chronic mortality risk in China based on multi-model exposure data. Environment International 110, 105-112.

Wei, Y., Davis, J., Bina, W.F., 2012. Ambient air pollution is associated with the increased incidence of breast cancer in US. International journal of environmental health research 22, 12-21.

Zhang, X., Yang, Q., Lin, G., Shen, J., Zhou, Q., Li, K., Dong, H., Song, S., Liu, B., Chen, Q., 2014. Grey relational analysis on association between urban air pollution and lung cancer in China. Chin. J. Public Health 30, 165-170.

Zhou, M., Wang, H., Zeng, X., Yin, P., Zhu, J., Chen, W., Li, X., Wang, L., Wang, L., Liu, Y., Liu, J., Zhang, M., Qi, J., Yu, S., Afshin, A., Gakidou, E., Glenn, S., Krish, V.S., Miller-Petrie, M.K., MountjoyVenning, W.C., Mullany, E.C., Redford, S.B., Liu, H., Naghavi, M., Hay, S.I., Wang, L., Murray, C.J.L., Liang, X., 2019. Mortality, morbidity, and risk factors in China and its provinces, 1990-2017: a systematic analysis for the Global Burden of Disease Study 2017. The Lancet. 


\section{Figure Legends}

Figure 1. The spatial distribution of cancer registries in 2014.

Figure 2. The spatial distribution of nineteen-year-long mean $\mathrm{PM}_{2.5}$ concentration in China.

Figure 3. The spatial distribution of morbidity and mortality of different cancers in 2014 across 307 registries. A and B for all cancer, C and D for breast cancer, E and F for pancreatic cancer.

Figure 4. The Moran's I statistics of different cancers mortality and morbidity in 2014. $\mathrm{A}$ and $\mathrm{B}$ for all cancer, $\mathrm{C}$ and $\mathrm{D}$ for breast cancer, $\mathrm{E}$ and $\mathrm{F}$ for pancreatic cancer.

Figure 5. The Moran's I statistics of PM2.5 from 2006 to 2014.

Figure 6. Predicted annual all cancer mortality and morbidity over China in 2015 and 2016. A and B for morbidity, C and D for mortality. A and C denotes the morbidity and mortality prediction in 2015 , respectively. B and D denotes the morbidity and mortality prediction in 2016, respectively.

Figure 7. Predicted annual breast cancer mortality and morbidity over China in 2015 and 2016. A and B for morbidity, C and D for mortality.

Figure 8. Predicted annual pancreatic cancer mortality and morbidity over China in 2015 and 2016. A and B for morbidity, C and D for mortality. 


\title{
Declarations
}

\begin{abstract}
Abbreviations
$\mathrm{PM}_{2.5}$ : Ambient fine particulate matter with diameter $<2.5 \mu \mathrm{m}$; YLL: years of life lost; NCCR: National Central Cancer Registry; PLSR: Partial least squares regression; PCA: principal component analysis; CCA: canonical correlation analysis; MLR: multiple linear regression; MSE: mean square error; RMSE: the root mean square error; MAE: mean absolute error; MAPE: mean absolute percentage error; Theil IC: Theil inequality coefficient; CP: covariance proportion; YRD: the Yangzi River Delta; BTH: BeijingTianjin-Hebei; NEC: Northeast China.
\end{abstract}

\section{Author E-mail address:}

Jay Pan (Corresponding author): panjie.jay@scu.edu.cn

Ke Ju: jako1993@163.com

WeiBin Liao: gymlwb@gmail.com

Qian Zhou: zhouqian_97@163.com

YaMin Gao: 1842533733@qq.com

\author{
Affiliations \\ ${ }^{1}$ West China School of Public Health and West China Fourth Hospital, Sichuan \\ University, Chengdu, China; \\ ${ }^{2}$ Medical College, Northwest Minzu University, Lanzhou, China; \\ ${ }^{3}$ West China Research Center for Rural Health Development, Sichuan University, \\ Chengdu, China.
}

\section{Acknowledgments}

We thank all the participants in our study.

\section{Funding}

This study was supported by the National Science Foundation of China (Grants No.: 71303165 and 71874116).

\section{Authors contributions}


KJ and WBL conceived this study. KJ and WBL designed the study. QZ and YMG collected documents and extracted data. WBL and KJ analyzed data and produced the figures and tables. KJ wrote the first draft of the paper. KJ, WBL, YG, QZ and JP revised the paper. All authors approved the final submitted version.

\section{Availability of data and materials}

The datasets used and analyzed during the current study are available from the corresponding author on reasonable request.

\section{Ethics approval and consent to participate}

Not applicable.

\section{Consent for publication}

Not applicable.

\section{Competing interests}

The authors declare that they have no competing interests 


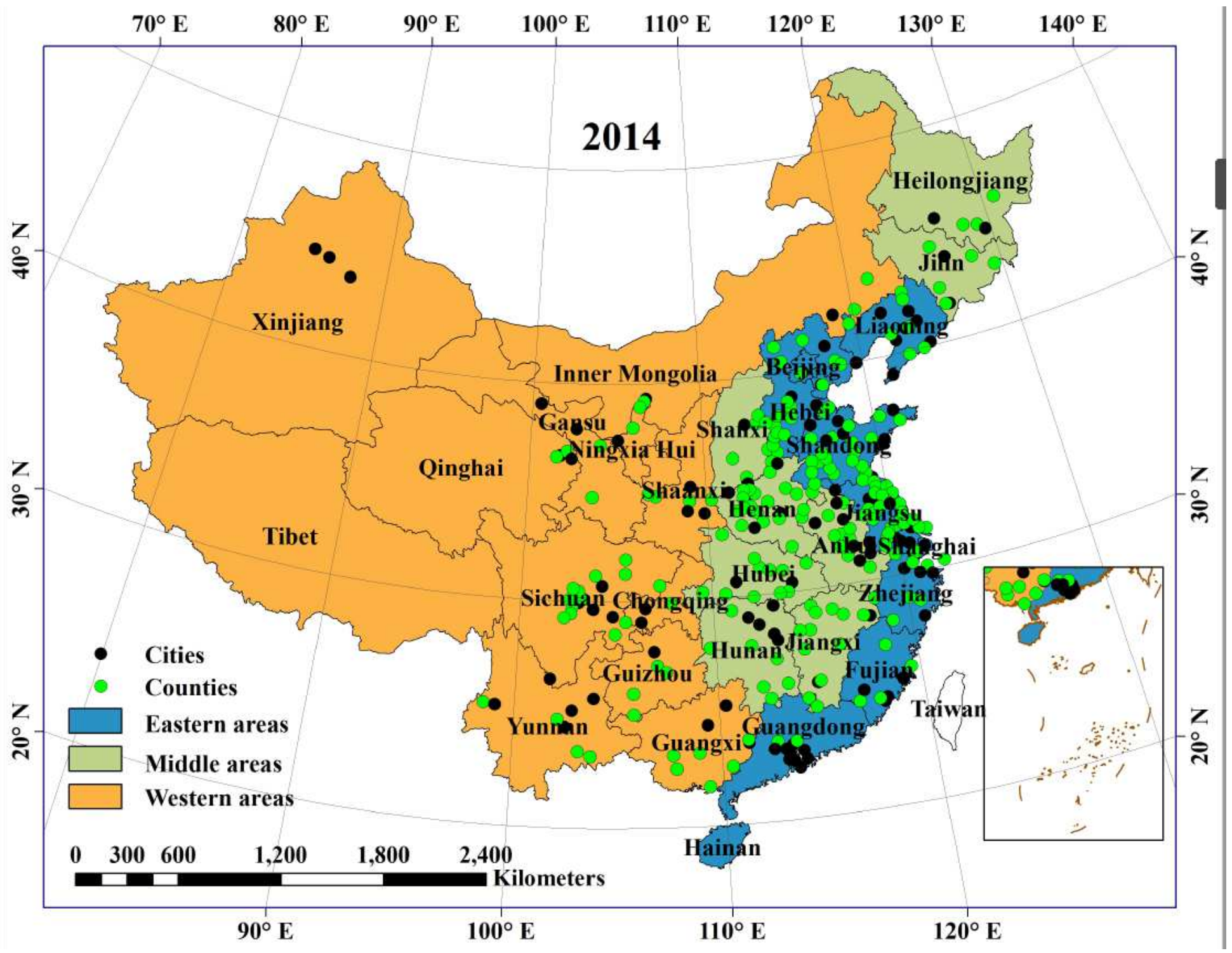

Figure 1

The spatial distribution of cancer registries in 2014. Note: The designations employed and the presentation of the material on this map do not imply the expression of any opinion whatsoever on the part of Research Square concerning the legal status of any country, territory, city or area or of its authorities, or concerning the delimitation of its frontiers or boundaries. This map has been provided by the authors. 


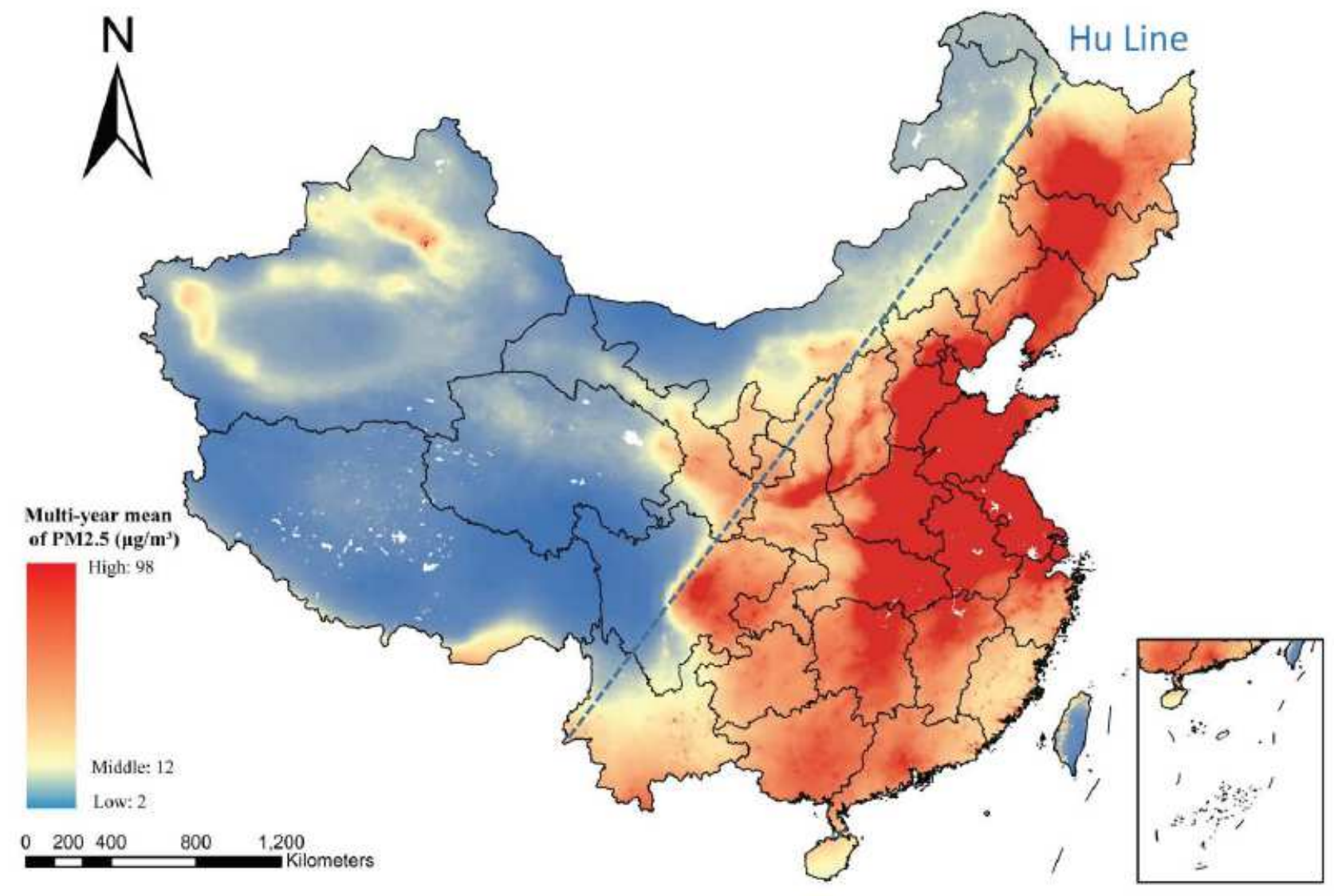

\section{Figure 2}

The spatial distribution of nineteen-year-long mean PM2.5 concentration in China. Note: The designations employed and the presentation of the material on this map do not imply the expression of any opinion whatsoever on the part of Research Square concerning the legal status of any country, territory, city or area or of its authorities, or concerning the delimitation of its frontiers or boundaries. This map has been provided by the authors.

\section{Figure 3}

The spatial distribution of morbidity and mortality of different cancers in 2014 across 307 registries. A and $\mathrm{B}$ for all cancer, $\mathrm{C}$ and $\mathrm{D}$ for breast cancer, $\mathrm{E}$ and $\mathrm{F}$ for pancreatic cancer. Note: The designations employed and the presentation of the material on this map do not imply the expression of any opinion whatsoever on the part of Research Square concerning the legal status of any country, territory, city or area or of its authorities, or concerning the delimitation of its frontiers or boundaries. This map has been provided by the authors. 

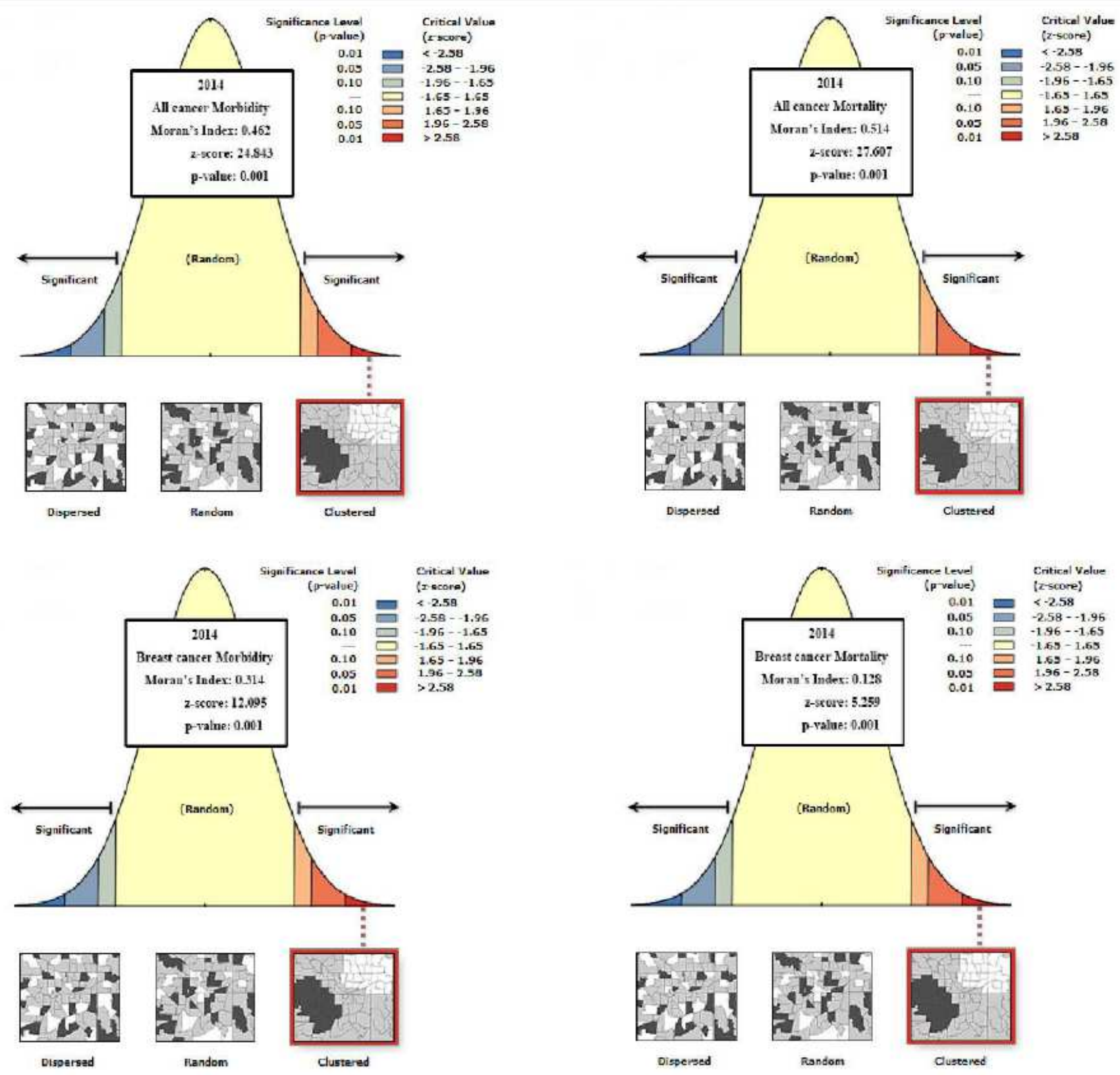

Figure 4

The Moran's I statistics of different cancers mortality and morbidity in 2014. A and B for all cancer, C and $\mathrm{D}$ for breast cancer, $\mathrm{E}$ and $\mathrm{F}$ for pancreatic cancer. 

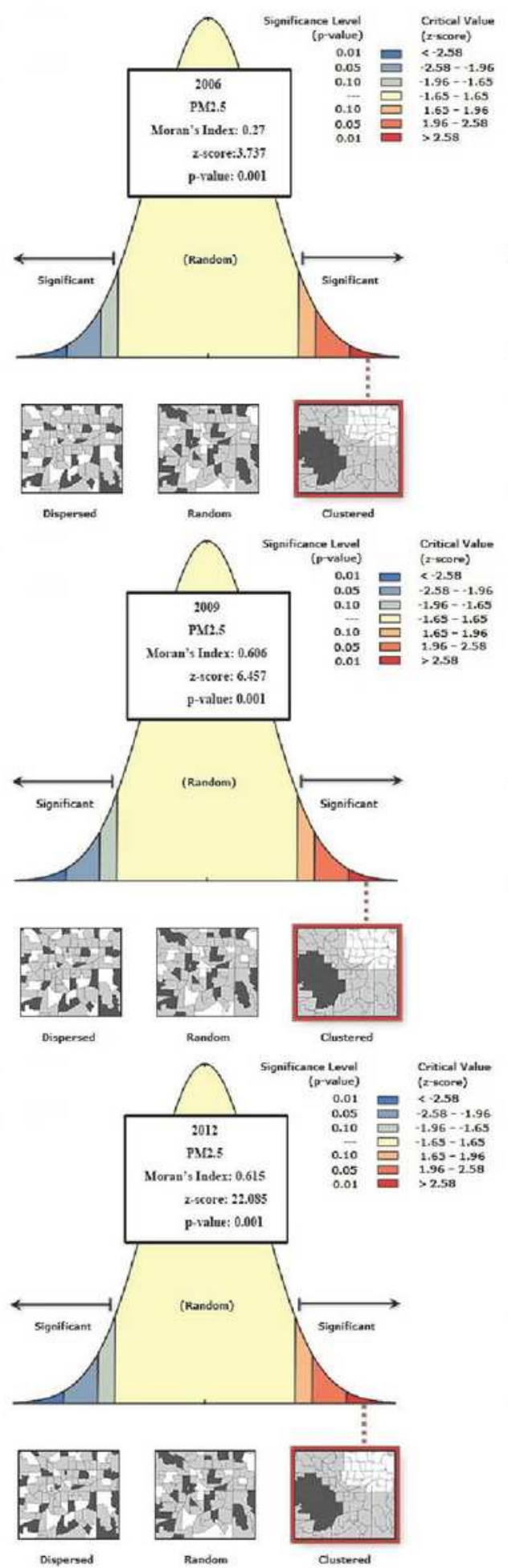
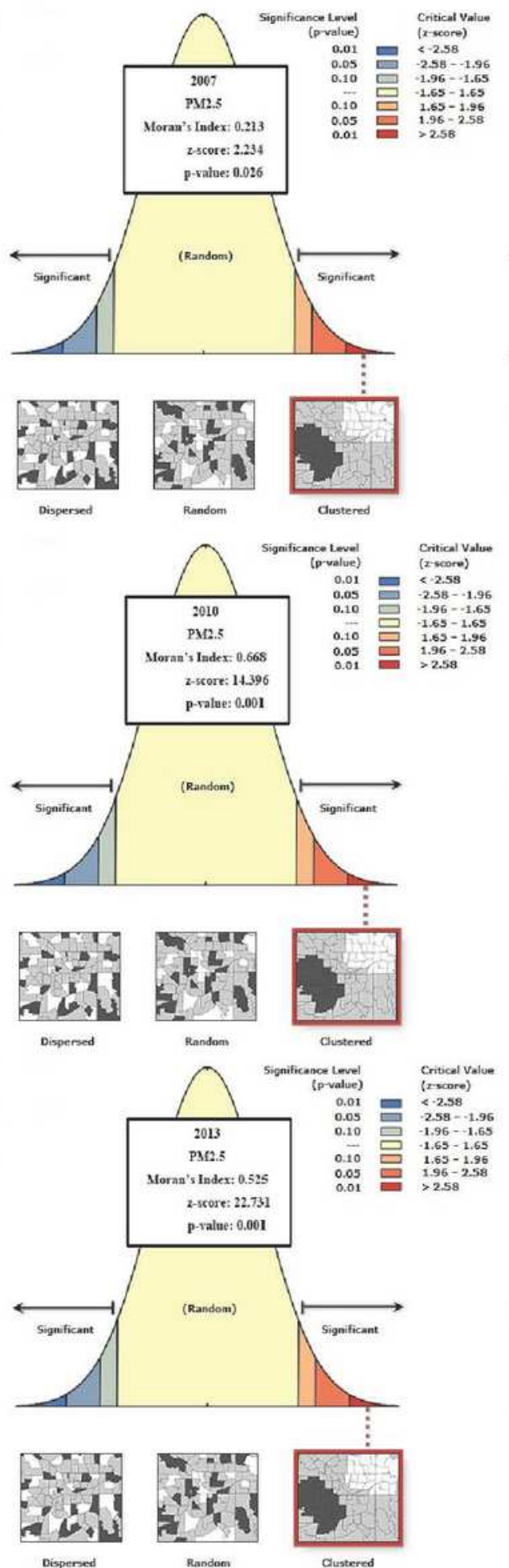
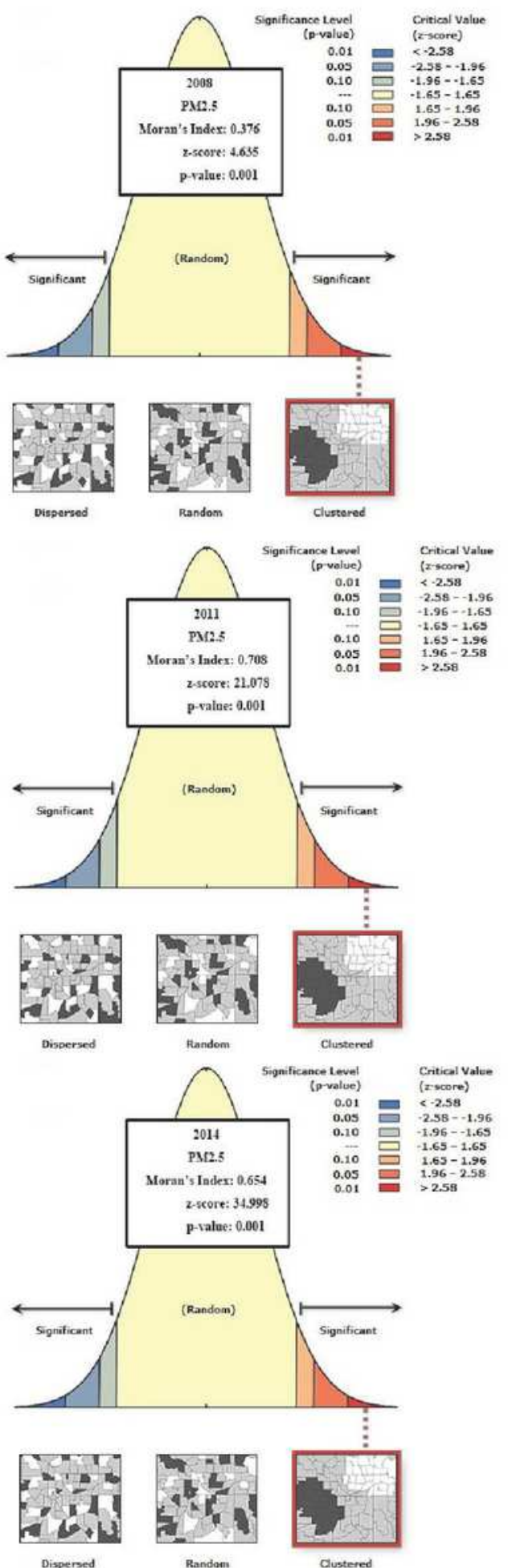

Figure 5

The Moran's I statistics of PM2.5 from 2006 to 2014. 

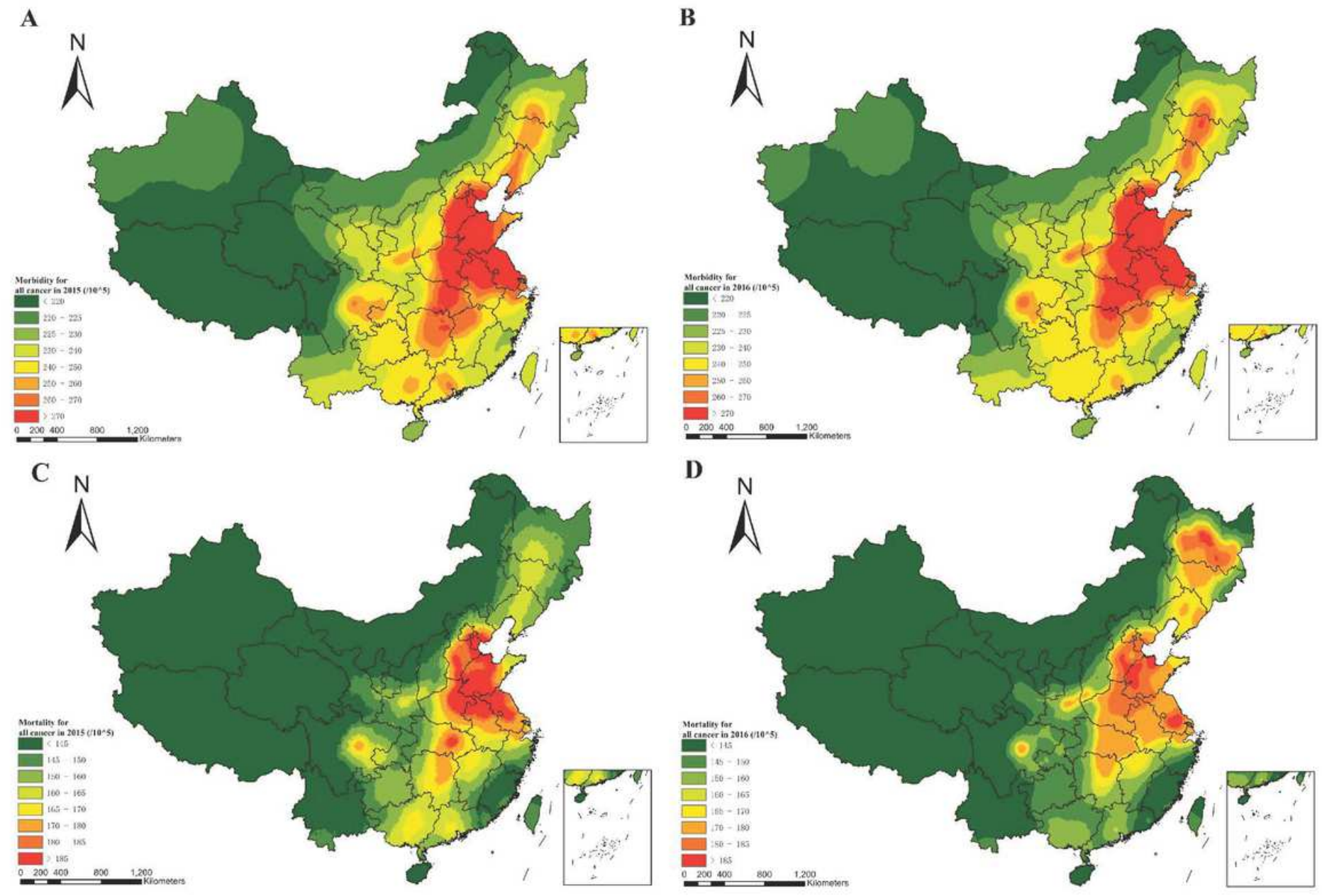

\section{Figure 6}

Predicted annual all cancer mortality and morbidity over China in 2015 and 2016. A and B for morbidity, C and $D$ for mortality. A and $C$ denotes the morbidity and mortality prediction in 2015 , respectively. $B$ and $D$ denotes the morbidity and mortality prediction in 2016, respectively. Note: The designations employed and the presentation of the material on this map do not imply the expression of any opinion whatsoever on the part of Research Square concerning the legal status of any country, territory, city or area or of its authorities, or concerning the delimitation of its frontiers or boundaries. This map has been provided by the authors. 
A

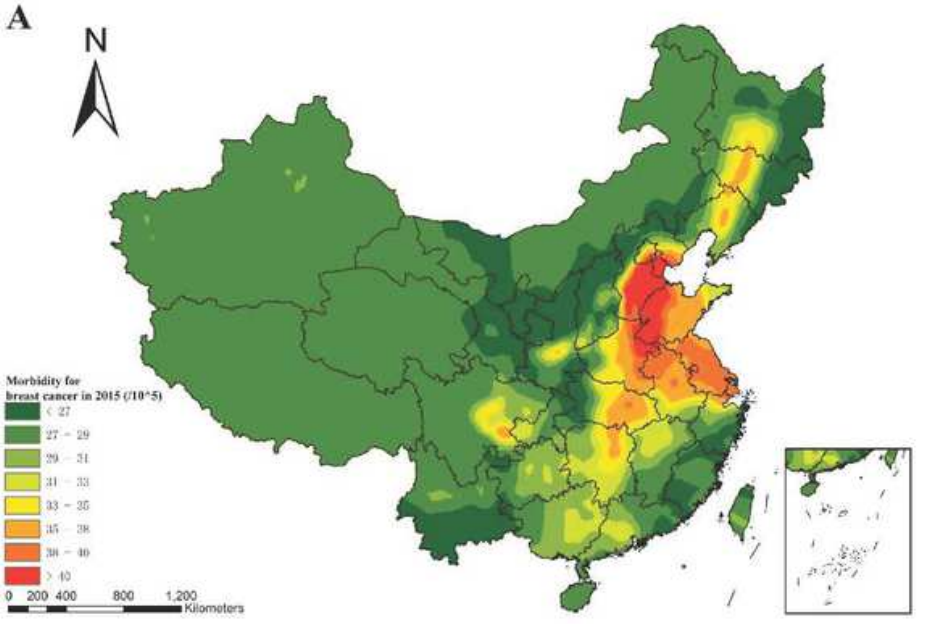

C N

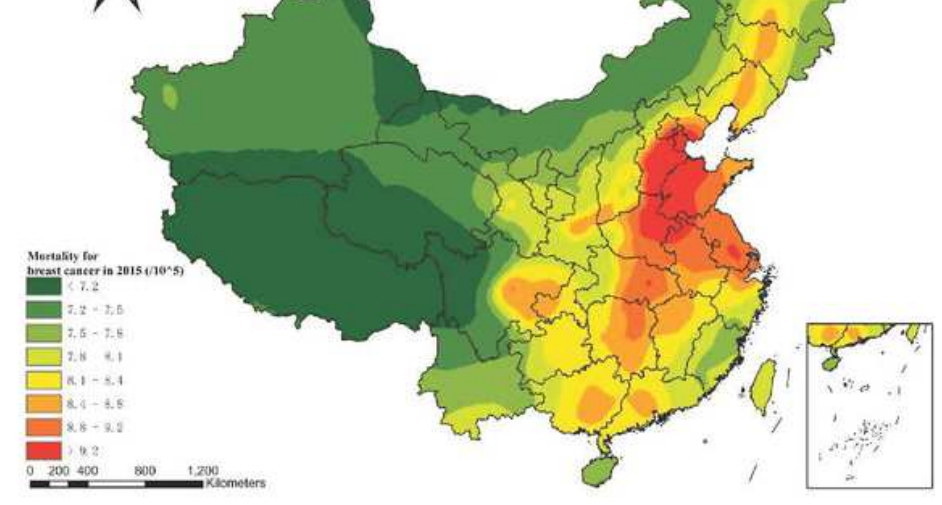

B

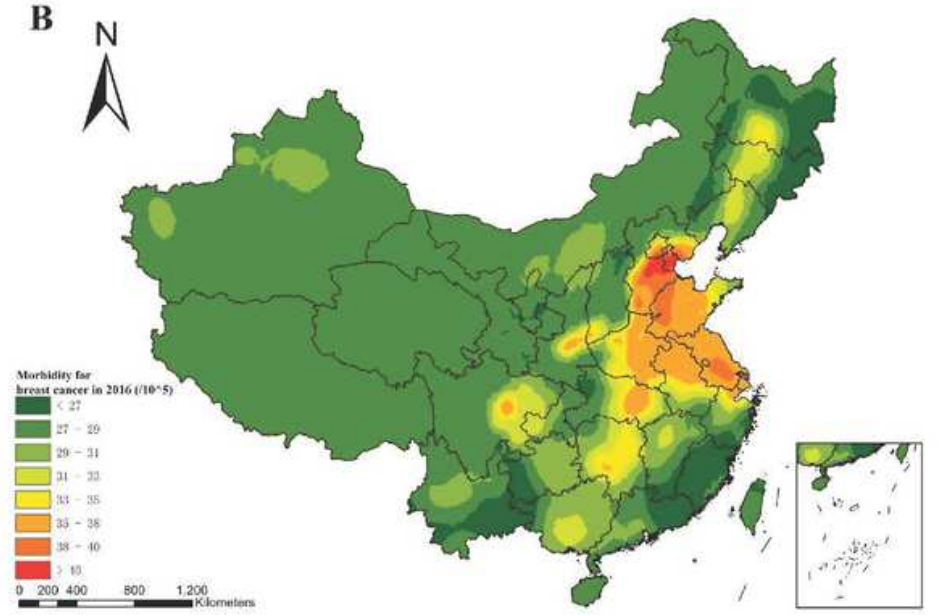

D

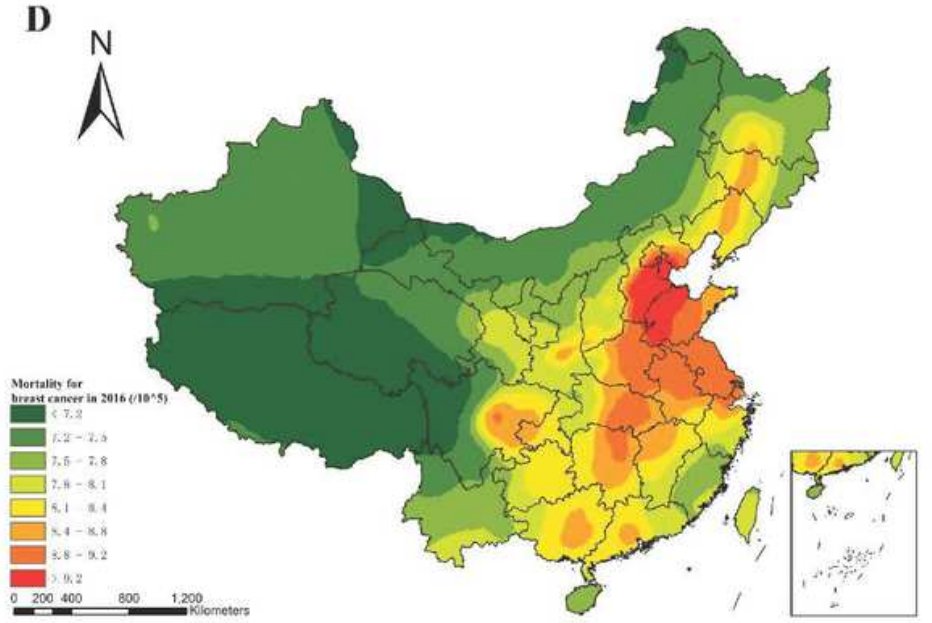

\section{Figure 7}

Predicted annual breast cancer mortality and morbidity over China in 2015 and 2016. A and B for morbidity, C and D for mortality. Note: The designations employed and the presentation of the material on this map do not imply the expression of any opinion whatsoever on the part of Research Square concerning the legal status of any country, territory, city or area or of its authorities, or concerning the delimitation of its frontiers or boundaries. This map has been provided by the authors. 

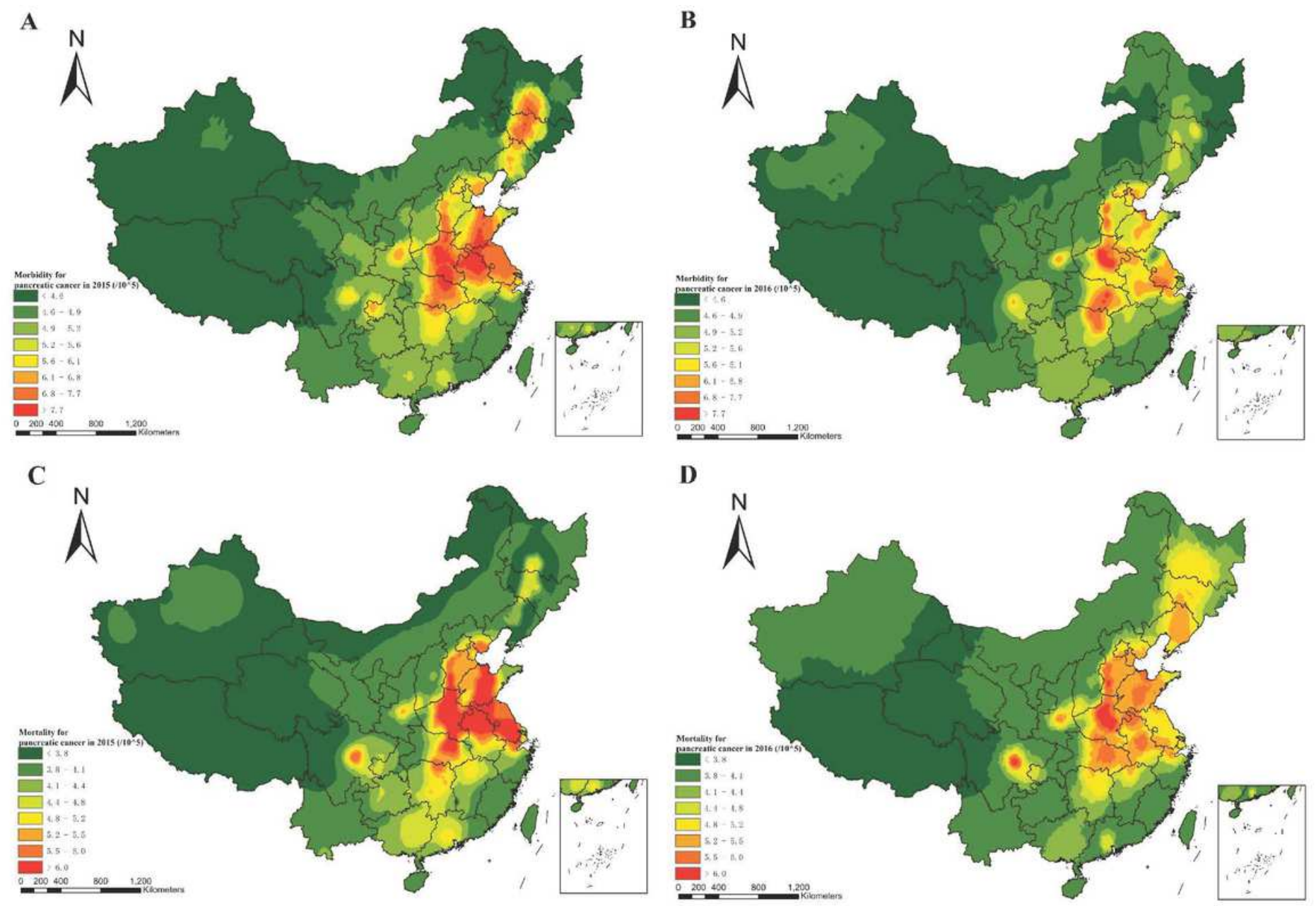

\section{Figure 8}

Predicted annual pancreatic cancer mortality and morbidity over China in 2015 and 2016. A and B for morbidity, $C$ and $D$ for mortality. Note: The designations employed and the presentation of the material on this map do not imply the expression of any opinion whatsoever on the part of Research Square concerning the legal status of any country, territory, city or area or of its authorities, or concerning the delimitation of its frontiers or boundaries. This map has been provided by the authors. 